\title{
Literasi Kesehatan Mental: Pengetahuan dan Persepsi Publik mengenai Gangguan Mental
}

\author{
Literacy of Mental Health: \\ Knowledge and Public Perception of Mental Disorders
}

\author{
Anita Novianty \\ Universitas Kristen Krida Wacana, Indonesia \\ *Corresponding author: E-mail: anita.novianty@ukrida.ac.id
}

\begin{abstract}
Abstrak
Prevalensi gangguan mental terus meningkat setiap tahun, akan tetapi banyak kasus tidak ditangani dengan penanganan profesional. Literasi kesehatan mental adalah salah satu faktor yang memengaruhi niat seseorang untuk mencari pertolongan profesional. Penelitian ini bertujuan untuk mengetahui pengetahuan dan persepsi publik mengenai gangguan mental (kasus depresi dan skizofrenia). Partisipan penelitian ini terdiri dari 89 orang (N=89; Laki-laki: 32, Perempuan: 57), berusia 15-38 tahun. Metode penelitian ini menggunakan survei online dengan memberikan dua vignette yang terdiri dari kasus depresi dan skizofrenia yang diadaptasi dari Angermeyer et al. (2005). Jawaban partisipan pada vignette menggambarkan pengetahuan dan persepsi publik, pilihan pencarian pertolongan, dan stigma. Statistik deskriptif dan analisis tema digunakan untuk analisis data. Hasil menunjukkan bahwa hanya $22,5 \%$ partisipan mengenali vignette sebagai depresi, walaupun $75,3 \%$ dari partisipan pernah melihat gejala yang mirip dengan vignette pada keluarga atau teman-temannya. Sementara itu, hanya 8,9\% partisipan mengenali vignette sebagai skizofrenia, walaupun $44,9 \%$ dari mereka pernah melihat gejala yang mirip dengan vignette pada keluarga/temannya. Selain itu hanya $23,6 \%$ partisipan merujuk keluarga/teman dengan gejala skizofrenia pada penanganan profesional, yang lain memilih untuk merujuk pada dukun. Tema terkait persepsi, pilihan pencarian pertolongan dan stigma dengan analisis tema akan dibahas kemudian.

Kata Kunci: depresi, kesehatan mental, pengetahuan, persepsi, skizofrenia
\end{abstract}

\section{Abstract}

The prevalence of mental illness was increasing every year, yet many cases were not treated by professional treatment. Mental health literacy is one of factors in which influence people's intention to seek professional treatment. This study aimed to find out the knowledge and public's perception about mental illness (depression \& schizophrenia case). The participants of this study was 89 people ( $N=89$; Men: 32, Women: 57), aged 15-38 years old. The method of this study was online survey that consisted of two vignettes about depression and schizophrenia case that were adapated from Angermeyer et al. (2005). Participant's responses on vignette described public's knowledge and perception, help-seeking references, and stigma. Descriptive statistics and thematic analysis were used to analyze data. The result showed only $21 \%$ of participants recognized vignette as depression, eventhough $81 \%$ of them ever met family/friends with similar symptoms on vignette. On the other hand, Only $12 \%$ of participants recognized vignette as schizophrenia, eventhough $45 \%$ of them ever met family/friend with similar symptoms on vignette. Only $25 \%$ of participants referred family/friend with schizophrenia symptoms to profesional treatment, the rest was reffered to informal treatment such as local healer. The theme of perception, help-seeking reference and stigma that were analyzed by thematic analysis will be disscussed later.

Keywords: depression, knowledge, mental health, perception, schizophrenia

How to Cite: Novianty, A. (2017), Literasi Kesehatan Mental: Pengetahuan dan Persepsi Publik Mengenai Gangguan Mental, ANALITIKA, Vol 9 (2): 68 - 75 


\section{PENDAHULUAN}

Prevalensi gangguan mental terus meningkat tiap tahunnya dan berkontribusi sebesar 23 persen dari beban penyakit dunia pada tahun 2010 (Becker \& Kleinman, 2013). Survei yang dilakukan di 17 negara menemukan ratarata satu dari 20 orang melaporkan memiliki episode depresi (World Health Organization, 2015). Sementara itu, prevalensi gangguan mental yang paling sering muncul di layanan kesehatan primer yaitu depresi, gangguan kecemasan menyeluruh, gangguan somatoform nonspesifik, dan dysthymia (Roca et al., 2009). Hasil estimasi yang dilakukan oleh McBain, Salhi, Morris, Salomon, dan Betancourt (2012) menunjukkan bahwa saat ini 450 ribu orang setidaknya memiliki satu gangguan mental.

Di Indonesia, hasil Riset Kesehatan Dasar (Riskedas) menunjukkan prevalensi gangguan jiwa berat nasional sebesar 1,7 per mil, yang artinya 1-2 orang dari 1000 penduduk Indonesia mengalami gangguan jiwa. Prevalensi penduduk yang mengalami gangguan mental emosional secara nasional pada tahun 2013 sebesar enam persen (37.728 orang dari subjek yang dianalisis). Prevalensi tertinggi ada pada kelompok usia lebih dari 75 tahun dibandingkan kelompok usia lainnya, kelompok perempuan daripada laki-laki, dan kelompok tidak sekolah (Kementerian Kesehatan RI, 2013).

Prevalensi individu dengan gangguan mental secara global maupun nasional dapat dikatakan tinggi, namun jumlah individu yang mendapatkan penanganan profesional kurang dari $10 \%$ di negaranegara dengan pendapatan menengah ke bawah (McBain et al., 2012). Tingginya angka beban tersebut salah satunya dikarenakan banyaknya individu tidak mendapatkan penanganan yang tepat di layanan spesialis maupun layanan kesehatan secara umum (Kohn, Saxena, Levav, \& Saraceno, 2004). Di banyak konteks negara-negara dengan pendapatan menengah ke bawah, gangguan mental lebih banyak ditangani oleh penyembuh tradisional (Burns, 2014). Penelitian di Afrika, Arab, Asia, dan India menunjukkan kebanyakan individu lebih memilih untuk mencari pertolongan ke penyembuh lokal terlebih dahulu sebelum mencoba jalur medis (Angermeyer, Breier, Dietrich, Kenzine, \& Matschinger, 2005; Ediriweera, Fernando \& Pai, 2012; Uwakwe \& Otakpor, 2014).

Ansseau et al. (2004) menyatakan bahwa meskipun hanya 5,4\% pasien yang mengunjungi dokter umum untuk kondisikondisi psikologis, namun kenyataannya didapatkan hampir $40 \%$ pasien memenuhi kriteria gangguan mental. Adanya kesenjangan antara alasan pasien datang ke dokter umum dan diagnosa yang aktual kemungkinan disebabkan beberapa faktor yaitu dokter umum memiliki waktu terbatas untuk mewawancarai pasien, pengetahuan yang belum memadai mengenai prosedur diagnosis gangguan mental, sering men "somatisasi"-kan gangguan-gangguan mental, dan kurangnya empati pada pasien dengan gangguan mental. Sementara di level pasien, adanya penolakan untuk mengkonsultasikan keadaan psikologis mereka akibat kekhawatiran dengan stigma.

Ditemukannya indikator kasus gangguan mental di layanan kesehatan primer adalah nyata adanya. Dapat 
Anita Novianty. Literasi Kesehatan Mental: Pengetahuan dan Persepsi Publik Mengenai Gangguan Mental

dikatakan bahwa di tingkat layanan kesehatan primer dasar dibutuhkan adanya layanan psikologi. Namun demikian, layanan psikologi yang diberikan di layanan kesehatan primer tidak serta merta dapat diterima dengan mudah dan efektif, dikarenakan literasi kesehatan mental masyarakat yang masih rendah, stigma yang melekat terkait gangguan mental, dan juga perlunya penguatan penggunaan teknik-teknik layanan psiko-logi yang cocok untuk dapat diterapkan di level dasar dan proses kerja di layanan kesehatan primer (Novianty \& Retnowati, 2016).

Munculnya urgensi untuk meningkatkan literasi kesehatan mental dikarenakan masih kurang dikenalinya gejala-gejala gangguan mental dibandingkan gangguan fisik, adanya kesenjangan antara keyakinan publik dan profesional terhadap penanganan gangguan mental, stigma, dan rendahnya kemampuan dalam keterampilan merespon orang lain dengan gejala gangguan atau krisis mental memengaruhi penundaan dan kekeliruan dalam mencari bantuan untuk penanganan gangguan mental (Jorm et al., 2006).

Jorm (2000) memperkenalkan istilah "literasi kesehatan mental" dan mendefinisikannya sebagai pengetahuan dan keyakinan mengenai gangguan mental yang membantu pengenalan, manajemen, atau prevensi. Berdasarkan definisi sebelumnya dan pengembangan konstrak literasi kesehatan mental dalam berbagai penelitian, saat ini literasi kesehatan mental didefinisikan sebagai: (a) pemahaman cara memeroleh dan menjaga kesehatan mental positif; (b) pemahaman gangguan mental dan penanganannya; (c) pengurangan stigma terkait gangguan mental; dan (d) meningkatkan efikasi pencarian pertolongan (mengetahui kapan dan di mana mencari pertolongan dan mengembangkan kompetensi untuk meningkatkan perawatan kesehatan mental seseorang dan kemampuan manajemen diri) (Kutcher, Wei, \& Coniglio, 2016).

\section{METODE PENELITIAN}

Studi deskriptif ini meneliti 89 responden dari 91 total responden. Dua responden digugurkan karena jawaban yang tidak lengkap. Responden dipilih dengan teknik convenient sampling, menggunakan survei dalam jaringan (online). Hal ini dimaksudkan agar responden lebih nyaman dan mudah memberikan jawaban secara deskriptif. Penelitian ini menggunakan dua vignette (depresi dan skizofrenia), serta kuesioner yang menyertainya.

Instrumen Penelitian

Dua vignette (depresi dan skizofrenia) yang digunakan dalam penelitian ini dimodifikasi dari vignette yang telah dikembangkan oleh Angermeyer et al. (2005). Vignette menggambarkan seseorang yang sesuai dengan kriteria diagnosis depresi mayor dan skizofrenia berdasarkan DSM-IV dan ICD-10. Vignette dapat diadministrasikan secara independen. Bersamaan dengan vignette tersebut, responden diminta menjawab pertanyaan yang bertujuan untuk mengetahui: a) kemampuan mengenai gangguan mental; b) penyebab terjadinya gangguan mental; c) Tipe rujukan/pencarian pertolongan; dan d) sikap terhadap orang dengan gangguan 
mental. Data demografi responden juga direkam oleh peneliti.

Analisis Data

Analisis deskriptif dengan perangkat lunak digunakan untuk analisis data. Analisis deskriptif dilakukan secara terpisah untuk tiap vignette. Frekuensi dari tiap respon atas pertanyaan tertutup dianalisis. Respon terhadap pertanyaan terbuka dikategorisasi untuk melihat tema yang muncul.

\section{HASIL DAN PEMBAHASAN}

Gambaran responden penelitian

Total responden berjumlah 89 orang $(\mathrm{n}=89$; laki-laki=32, dan perempuan=57). Kisaran usia responden 15-38 tahun. Sebagian besar responden berpendidikan terakhir di perguruan tinggi (63\%), sekolah menengah atas $(25 \%)$ dan tidak teridentifikasi (12\%). Sebagian besar responden masih sekolah atau tidak bekerja (51\%), sementara lainnya bekerja sebagai guru atau pegawai swasta (51\%). Kategorisasi jawaban responden

Jawaban responden dikategorisasi ke dalam empat bagian yaitu: a) Pengenalan gangguan mental; b) Penyebab gangguan mental; dan c) Tipe rujukan/pencarian pertolongan; dan d) Sikap terhadap orang dengan gangguan mental.

a) Pengenalan gangguan mental

Berdasarkan hasil kategorisasi diketahui sebagian besar mengenal vignette depresi sebagai situasi yang menekan/sulit (67\%), hanya sebagian kecil yang tepat memberikan label depresi (21\%), sementara lainnya menyebutkan jenis gangguan mental lain dan gangguan fisik (12\%). Pada kasus vignette skizofrenia masih banyak yang memberikan label tidak tepat (34\%).
Beberapa responden mampu melabeli dengan tepat (12\%), walaupun masih lebih banyak yang memberikan pelabelan gangguan mental secara umum (29\%), dan lainnya memberikan label tipe gangguan mental yang tidak tepat (25\%).

Masyarakat secara umum masih menghadapi kendala dalam mengenali gangguan-gangguan mental dengan tepat (Dahlberg, Waern, \& Runeson, 2008; Lauber, Nordt, \& Rössler, 2005). Berdasarkan studi populasi yang dilakukan di Swedia ditemukan hanya 2/3 populasi umum yang mengenali tandatanda depresi. Rekognisi yang rendah ini ada pada orang yang sehat dan juga yang memiliki gejala gangguan mental (Dahlberg et al., 2008). Penelitian yang sama pada etnis China menunjukkan persentase rendah pada literasi Skizofrenia yang berkaitan dengan pencarian pengobatan pada ahli herbal dalam menangani kasus tersebut (Wong \& Xuesong, 2011).

b) Penyebab gangguan mental

Pada vignette depresi, sebagian responden menjelaskan penyebab depresi berasal dari situasi internal individu (51\%) meliputi pikiran negatif, suasana hati yang buruk, dan terkait kurangnya iman. Sementara lainnya menjelaskan penyebab depresi berasal dari situasi eksternal (49\%) meliputi masalah di pekerjaan atau keluarga/teman. Sementara itu, pada vignette skizofrenia, penyebab justru banyak dijelaskan dari faktor sosial seperti tekanan dari pekerjaan, keluarga atau relasi, bahkan akibat gangguan roh/makhluk halus (98\%).

Di negara-negara Barat, depresi dan skizofrenia banyak dikenali publik akibat 
dari tekanan dalam kehidupan sehari-hari. Hal ini berbeda dengan pandangan psikiater yang menekankan pentingnya tekanan hidup sebagai pemicu munculnya gejala-gejala, akan tetapi bukanlah penyebab. Hasil studi menemukan bahwa gejala skizofrenia banyak dipahami oleh masyarakat umum sebagai akibat dari faktor biologis dibandingkan faktor psikososial. Perbedaan muncul di negara dengan budaya non-barat yang lebih banyak meyakini fenomena supranatural sebagai penyebab gangguan mental.

Keyakinan mengenai penyebab akan memengaruhi perilaku mencari bantuan dan bagaimana mereka merespon terhadap penanganan. Sebagai contoh, keyakinan orang-orang awam di Malaysia bahwa penyebab gangguan mental akibat dari supranatural, maka penanganan yang dilakukan adalah dengan cara mendatangi penyembuh tradisional ("orang pintar") dan sangat sedikit mendapatkan pengobatan medis (Jorm, 2000). Keyakinan penyebab gangguan mental akibat faktor biologis lebih meningkatkan intensi untuk mencari bantuan ke tenaga profesional dibandingkan keyakinan gangguan mental akibat faktor personal untuk kasus skizofrenia (Wrigley, Jackson, Judd, \& Komiti, 2005).

c) Tipe rujukan/pencarian pertolongan

Pada kasus vignette depresi sebagian besar responden merujuk individu di dalam vignette pada tipe pertolongan informal seperti mengajak berbicara atau melakukan ritual keagamaan (98\%). Pada kasus vignette skizofrenia, sebagian besar merujuk individu dalam vignette ke pertolongan informal seperti pertolongan diri sendiri atau ahli agama, hanya sebagian kecil yang merujuk ke dokter/ahli profesional lainnya (25\%), lainnya tidak teridentifikasi (2\%).

Beberapa survei yang menanyakan pada masyarakat umum di negara maju mengenai berbagai bantuan profesional menunjukkan bahwa untuk menangani depresi, masyarakat umum akan mencari bantuan dokter umum. Sementara psikiater dan psikolog kurang dipilih dibandingkan dokter umum, terkecuali untuk gejala skizofrenia. Keyakinan akan bantuan profesional kemungkinan berbeda di negara berkembang. Seperti di Ethiopia, sumber pertolongan tradisional seperti, air suci dan herbal lebih dipilih daripada pengobatan medis. Hal ini dikarenakan adanya anggapan bahwa pengobatan medis hanya untuk gangguan fisik saja.

d) Sikap terhadap orang dengan gangguan mental

Hal yang menarik ditemukan dalam penelitian ini bahwa sebagian besar responden pernah menemui keluarga/teman/tetangga yang mengalami gejala seperti dalam vignette depresi (81\%). Ada keyakinan bahwa individu dalam vignette depresi tersebut dapat sembuh/kembali normal (98\%) dan tidak membahayakan orang lain (67\%). Bahkan sebagian besar responden masih mau berteman dengan individu dalam vignette depresi tersebut (72\%). Hal ini mengindikasikan stigma publik pada vignette depresi cenderung rendah. Sementara itu pada vignette skizofrenia hampir sebagian besar responden menyatakan bahwa individu dalam vignette berbahaya bagi orang lain (78\%), walaupun menariknya sebagian dari mereka masih mau berteman dengan individu tersebut. Hasil penelitian 
menunjukkan bahwa sebagian pernah menemui keluarga/teman/tetangga yang memiliki gejala mirip dalam vignette tersebut (45\%). Hal ini menunjukkan bahwa adanya stigma negatif pada individu yang dianggap memiliki gangguan skizofrenia.

Stigma diri dan stigma publik memengaruhi kecenderungan untuk mencari pertolongan profesional dan sebaliknya (Gearing et al., 2015). Stigma tidak hanya terjadi di masyarakat umum, namun juga di kalangan profesional kesehatan yang disebabkan oleh kurangnya pengetahuan dan citra negatif yang dibentuk media (Hanafiah \& Bortel, 2015). Menurut Barczyk (2015), pengalaman berkontak dengan pasien gangguan mental dikatakan dapat memengaruhi keyakinan seseorang akan tingkat kepulihan seorang pasien gangguan mental yang nantinya akan memprediksi jarak sosialnya.

Pengetahuan mengenai gangguan mental adalah indikator yang kuat terhadap pengetahuan mengenai pilihanpilihan penanganan dan keyakinan mengenai gangguan mental (Jorm et al., 2000; Lauber et al., 2003; Wright, Jorm, Harris, \& McGorry, 2007). Pelabelan terhadap gangguan mental ditemukan terkait dengan identifikasi kebutuhan pencarian pertolongan dari tenaga profesional (Lauber et al., 2003; Wright et al., 2007). Dengan kata lain, pengenalan yang tepat terkait gangguan mental berhubungan dengan kecenderungan pemilihan strategi pengatasan masalah ke tenaga profesional. Pengetahuan mengenai gangguan mental akan mendorong seseorang mencari pertolongan dari tenaga formal dibandingkan informal (Kutcher et al., 2016). Literasi kesehatan mental dan sikap komunitas juga ditemakuan sebagai prediktor yang signifikan dalam pencarian pertolongan formal (Novianty \& Hadjam, 2017).

Penelitian uji model yang dilakukan Kutcher et al. (2016) menemukan asosiasi kuat antara aspek pengenalan, penyebab, dan keyakinan pencarian pertolongan formal dan informal yang terdapat dalam model literasi kesehatan mental. Keyakinan penyebab gangguan mental dari faktor biologis berkaitan dengan pencarian pertolongan formal. Penelitian ini juga menemukan adanya kontribusi budaya pada literasi kesehatan mental yaitu keyakinan akan pencarian pertolongan informal berasosiasi dengan aspek dalam literasi kesehatan mental pada sampel Indian, namun tidak signifikan pada sampel etnis EropaAmerika. Orientasi budaya kolektif berasosiasi signifikan dengan keyakinan penyebab sosial dibandingkan biologis dan pencarian pertolongan informal.

\section{SIMPULAN}

Berdasarkan telaah deskriptif dari hasil penelitian, maka dapat disimpulkan bahwa literasi kesehatan mental public masih tergolong rendah. Hal ini ditandai rendahnya pengenalan gangguan mental, keyakinan akan penyebab yang masih menekankan pada tekanan hidup seharihari atau faktor sosial, hingga tipe rujukan pertolongan ke pertolongan informal. Ada perbedaan stigma publik antara depresi yang masih dapat berterima di masyarakat, sementara skizofrenia yang lebih mendapat stigma negatif. Hal ini semakin perlu diperhatikan karena 
sebagian besar dari responden penelitian pernah menemui gejala dalam vignette pada orang terdekatnya. Penelitian selanjutnya perlu lebih menggali peran faktor demografi dan budaya setempat dalam memaknai pengenalan, penyebab, dan model pencarian pertolongan terkait gangguan mental.

\section{DAFTAR PUSTAKA}

Angermeyer, M.C., Breier, P., Dietrich, S., Kenzine, D., \& Matschinger, H. (2005). Public attitudes toward psychiatric treatment: An international comparison. Social Psychiatry and Psychiatric Epidemiology, 40(11), 855-864.

Barczyk, A. N. (2015). Relationship between the public's belief in recovery, level of mental illness stigma, and previous contact. Community Mental Health Journal, 51, 3847.

Becker, A.E., \& Kleinman, A. (2013). Global health: Mental health and the global agenda. The New England Journal of Medicine,369(1), 66-73.

Burns, J.K. (2014). The burden of untreated mental disorders in KwaZulu-Natal ProvinceMapping the treatment gap. South African Journal of Psychology, 2o(1), 6-10.

Dahlberg, K. M., Waern, M., \& Runeson, B. (2008). Mental health literacy and attitudes in a Swedish community sample - Investigating the role of personal experience of mental health care. BMC Public Health, 8(8), 1-10.

Ediriweera, H.W., Fernando, S.M., \& Pai, N.B. (2012). Mental health literacy survey among Sri Lankan carers of patients with schizophrenia and depression. Asian Journal of Psychiatry,5, 246-250.

Gearing, R. E., MacKenzie, M. J., Ibrahim, R. W., Brewer, K. B., Batayneh, J. S., \& Schwalbe, C. S. J. (2015). Stigma and mental health treatment of adolescents with depression in Jordan. Community Mental Health Journal, 51, 111-117.

Hanafiah, A. N., \& Bortel, T. V. (2015). A qualitative exploration of the perspectives of mental health professionals on stigma and discrimination of mental illness in Malaysia. International Journal of Mental Health Systems, 9(10), 1-12.
Jorm, A.F. (2000). Mental health literacy: Public knowledge and beliefs about mental disorders. British Journal of Psychiatry, 177, 396-401.

Jorm, A.F., Barney, L.J., Christensen, H., Highet, N.J., Kelly, C.M., \& Kitchener, B.A. (2006). Research on mental health literacy: What we know and what we still need to know. Australian and New Zealand Journal of psychiatry, 40, 3-5.

Kementrian Kesehatan RI. (2013). Riset Kesehatan Dasar (RISKESDAS) 2013. Laporan Penelitian (tidak dipublikasikan). Jakarta: Badan Penelitian dan Pengembangan Kesehatan.

Kohn, R., Saxena, S., Levav, I., \& Saraceno, B. (2004). The treatment gap in mental health care. Bulletin of the World Health Organization, 82(11), 858-866.

Kutcher, S., Wei, Y., \& Coniglio, C. (2016). Mental health literacy: Past, present, and future. The Canadian Journal of Psychiatry, 61(3), 154-158.

McBain, R., Salhi, C., Morris, J.E., Salomon, J.A., \& Betancourt, T.S. (2012). Disease burden and mental health system capacity: WHO atlas study of 117 low- and middle- income countries. The British Journal of Psychiatry, 201, 444-450.

Novianty, A., \& Hadjam, M.N.R. (2017). Literasi kesehatan mental dan sikap komunitas sebagai prediktor pencarian pertolongan formal. Jurnal Psikologi, 44(1), 50-65.

Novianty, A., \& Retnowati, S. (2016). Intervensi psikologi di layanan kesehatan primer. Buletin Psikologi, 24(1), 49-63.

Roca, M., Gili, M., Garcia-Garcia, M., Salva, J., Vives, M., Campayo, G., \& Comas, A. (2009). Prevalence and comorbidity of common mental disorders in primary care. Journal of Affective Disorders, 119, 52-58.

Uwakwe, \& R., \& Otakpor, A. (2014). Public mental health: Using the mental health gap action program to put all hands to the pumps. Frontier Public Health, 2(33), 1-19.

World Health Organization. (2015). Mental Health Atlas 2014. Geneva: WHO Library Cataloguing-in-Publication Data.

Wrigley, S., Jackson, H., Judd, F., \& Komiti, A. (2005). Role of stigma and attitudes toward help-seeking from a general practitioner for mental health problems in a rural town. Australian and New Zealand Journal of Psychiatry, 39, 514-521. 
Anita Novianty. Literasi Kesehatan Mental: Pengetahuan dan Persepsi Publik Mengenai Gangguan Mental

Wright, A., Jorm, A. F., Harris, M. G., \& McGorry, P. D. (2007). What's in a name? Is accurate recognition and labelling of mental disorders by young people associated with better help-seeking and treatment preferences? Social Psychiatry and Psychiatric Epidemiology, 42, 244-250.

Wong, D. F. K., \& Xuesong, H. (2011). Schizophrenia literacy among Chinese in Shanghai, China: A comparison with Chinese-speaking Australians in Melbourne and Chinese in Hong Kong. Australian and New Zealand Journal of Psychiatry, 45, 524531. 